\title{
Leptin-induced adhesion and invasion in colorectal cancer cell lines
}

\author{
KYUNG-WON YOON*, SEON-YOUNG PARK*, JI-YOUNG KIM, SU-MI LEE, CHANG-HWAN PARK, \\ SUNG-BUM CHO, WAN-SIK LEE, YOUNG-EUN JOO, JAE-HYUK LEE, \\ HYUN-SOO KIM, SUNG-KYU CHOI and JONG-SUN REW \\ Department of Internal Medicine, Chonnam National University Medical School, \\ Dong-ku, Gwangju 501-757, Republic of Korea
}

Received January 10, 2014; Accepted March 13, 2014

DOI: $10.3892 /$ or. 2014.3128

\begin{abstract}
Leptin, which is encoded by the obese gene, is a multifunctional neuroendocrine peptide that regulates appetite, bone formation, reproductive function and angiogenesis. The aims of the present study were to investigate the expression of leptin in 80 patients with colorectal cancer (CRC) and to determine the effects of leptin on the malignant properties of CRC cells. We evaluated the expression of leptin in tissues of 80 patients with CRC. Suspension cultures were used to isolate CRC stem cells following pretreatment with leptin. We analyzed the effects of leptin on the adhesion and invasive capacities of CRC cell lines. The effects of leptin on JAK and ERK activation were examined using western blotting. Leptin expression was associated with CRC progression and increased the number and size of spheroid formation by CRC cell lines. Leptin enhanced cell invasion and adhesion and activated JAK and ERK signaling in the CRC cell lines. The present study demonstrated that leptin influences the growth and survival of CRC stem cells and regulates adhesion and invasion of colorectal carcinoma through activation of the JAK and ERK signaling pathways.
\end{abstract}

\section{Introduction}

Colorectal cancer (CRC) is one of the most common neoplasms worldwide (1). A large body of epidemiological evidence suggests that obesity increases CRC risk in men (relative risks of $\sim 1.5-2.0$ ) and women (relatively risks of $\sim 1.2-1.5)(2,3)$. Although the molecular mechanisms underlying this association are unknown, data acquired from experiments performed in vitro suggest the direct involvement of fat tissue in CRC

Correspondence to: Professor Hyun-Soo Kim, Department of Internal Medicine, Chonnam National University Medical School, 42 Jaebongro, Dong-ku, Gwangju 501-757, Republic of Korea E-mail: dshskim@jnu.ac.kr

*Contributed equally

Key words: leptin, colorectal cancer, stem cell development. Adipocytes and preadipocytes stimulate the growth of CRC cells (4), and the principal hormone synthesized by adipocytes is leptin. Leptin is encoded by the obese gene and functions as a neuroendocrine hormone that has attracted attention since its identification in 1995 (5). Leptin regulates appetite, bone formation, reproduction and angiogenesis (6). These biological activities suggest that it plays an important role in proliferation, invasion and metastasis of cancer cells (7). In humans, circulating leptin levels correlate with body mass index and are significantly elevated in obese individuals (8). Recent data clearly indicate that the mitogenic, anti-apoptotic, proinflammatory and angiogenic properties of leptin promote the development and progression of different types of cancers (9). Several reports have described the mitogenic effects of leptin on gastric (10), breast (11), ovarian (12), prostate (13) and endometrial cancer cells (14). Two studies demonstrated that increased leptin levels are associated with greater risk of CRC development, particularly in males $(15,16)$. Furthermore, in colon epithelial cells, leptin was found to induce chemokine production associated with macrophage activation similar to that observed in an adenomatous polyposis coli genotype $(17,18)$. The aims of the present study were to investigate the expression of leptin in 80 patients with CRC and to determine the effects of leptin on the malignant properties of CRC cell lines.

\section{Materials and methods}

Case selection and immunohistochemical assessment. For immunohistochemical staining, we obtained formalin-fixed, paraffin-embedded tissue samples from 80 patients diagnosed with CRC at Chonnam National University Hospital, Gwangju, Korea. The histology of the tumors was analyzed, and the pathological stage was estimated according to the TNM score. Patients (stage I, $n=20$; stage $I, n=20$; stage III, $n=20$ and stage IV, n=20) were randomly selected from each of the stage categories. The specimens were fixed in $10 \%$ neutral-buffered formalin, embedded in paraffin and stained with hematoxylin and eosin. The present study was approved by the Institutional Review Board of Chonnam National University Hospital.

For immunohistochemical staining, tissue sections were deparaffinized, rehydrated and subjected to epitope retrieval. 
To block endogenous peroxidase activity, tissues were treated with Peroxidase-Blocking solution (Dako, Carpinteria, CA, USA) and incubated with a polyclonal rabbit anti-leptin antibody (A-20; Santa Cruz Biotechnology, Santa Cruz, CA, USA), which was diluted 1:100 using goat serum and incubated with the sections at room temperature for $1 \mathrm{~h}$. After three 2-min washes with phosphate-buffered saline (PBS), the sections were incubated with a biotinylated goat anti-rabbit secondary antibody for $30 \mathrm{~min}$ (Dako). After three 2-min washes in PBS, horseradish peroxidase-streptavidin (Dako) was added to the sections for $30 \mathrm{~min}$, followed by another three washes for 2 min in PBS. Reactions were detected using with 3,3'-diaminobenzidine substrate (Vector Laboratories, Burlington, ON, Canada) for $1 \mathrm{~min}$, and the cells were counterstained using Mayer's hematoxylin. Then slides were dehydrated following a standard procedure and sealed with coverslips.

Tissue specimens reacted with the anti-leptin antibody were examined at low and then at high magnification by two pathologists blinded to the identities of the samples. In cases of heterogeneous patterns in some sections, the classification was determined by the dominant pattern, and the intensity of stained cells was designated as negative, weak, moderate or strong.

Cell culture and leptin pretreatments. We selected three human CRC cell lines (LS174T, HCT 116 and CaCo-2) since they express leptin at high levels. They were obtained from the Korean Cell Line Bank (KCLB) and cultured at $37^{\circ} \mathrm{C}$ in a humidified atmosphere containing $5 \% \mathrm{CO}_{2}$. Cells were grown in Dulbecco's modified Eagle's medium (DMEM) containing 4,500 mg/l glucose, $100 \mathrm{mg} / 1$ streptomycin and $2 \mathrm{mM}$ L-glutamine supplemented with $10 \%$ fetal bovine serum (FBS) (both from Gibco Invitrogen Inc., USA). After $24 \mathrm{~h}$ of serum starvation, the culture media were replaced with serum-free media containing the indicated treatments. After a further $24 \mathrm{~h}$ incubation, $10 \mathrm{ng} / \mathrm{ml}$ human recombinant leptin (Sigma-Aldrich Corp., St. Louis, MO, USA) was added for different times.

Spheroid formation assay. Cells were grown to $70 \%$ confluence, trypsinized and plated in $100 \mathrm{~cm}^{2}$ diameter culture dishes at a density of 1,000 cells $/ \mathrm{ml}$ in serum-free DMEM containing $10 \mathrm{ng} / \mathrm{ml}$ human recombinant basic fibroblast growth factor, (bFGF) and $10 \mathrm{ng} / \mathrm{ml}$ human epidermal growth factor (hEGF) (both from R\&D Systems, Minneapolis, MN, USA). A density of at least 1,000 cells $/ \mathrm{ml}$ was established for forming tumorspheres/colonospheres (serving as an in vitro model of cancer stem cells). All cultures were incubated at $37^{\circ} \mathrm{C}$ in a humidified atmosphere containing $5 \% \mathrm{CO}_{2}$. Cells were grown as suspension cultures for 1-2 weeks for tumorsphere formation. Colonies were counted in 10 randomly selected fields at x 10 magnification using an Olympus IX50 inverted microscope.

Western blotting. To extract proteins, cells were lysed with RIFA buffer (1 M Tris-HCl, $150 \mathrm{mM} \mathrm{NaCl,} 1 \%$ Triton X-100 and $2 \mathrm{mM}$ EDTA) containing $1 \mathrm{mM}$ phenylmethanesulfonyl fluoride (PMSF) and Halt ${ }^{\mathrm{TM}}$ protease inhibitor cocktail (Thermo, Rockford, IL, USA). The protein concentrations of the cell lysates were quantitated using the $\mathrm{BCA}^{\mathrm{TM}}$ protein assay (Thermo) with bovine serum albumin (BSA) as a standard.
The lysates ( $25 \mu \mathrm{g}$ protein) were subjected to electrophoresis on 10\% SDS-polyacrylamide gels and then electrophoretically transferred to polyvinylidene fluoride membranes (Millipore, Billerica, MA, USA). The membranes were incubated for $1 \mathrm{~h}$ in blocking solution [5\% BSA in TBS-Tween-20 buffer (TBST)] and sequentially blotted with primary antibodies at $4^{\circ} \mathrm{C}$ overnight. Antibodies against Janus kinase 2 (JAK2), phospho-JAK2, AKT, phospho-AKT, ERK, phospho-ERK, MAPK, phospho-MAPK and $\beta$-actin were purchased from Cell Signaling Technology (Beverly, MA, USA). After rinsing in TBST, membranes were incubated with horseradish peroxidase (HRP)-labeled anti-rabbit or anti-mouse immunoglobulin secondary antibodies (1:2,000 dilution) (Cell Signaling Technology) at room temperature for $1 \mathrm{~h}$. Enhanced chemiluminescence was used to detect the bands, which were visualized using a Fuji LAS-3000 image analyzer (Fuji Film, Tokyo, Japan).

Adhesion assay. The 96-well plates were prepared. Three human CRC cell lines were detached from the surfaces of culture flasks with $5 \mathrm{mM}$ EDTA in PBS, resuspended in culture medium containing $0.02 \%$ BSA to $2.4 \times 10^{5}$ cells $/ \mathrm{ml}$, and $100 \mu \mathrm{l}$ of cell suspension was added to each well. All cells were assayed in quadruplicate. After incubation for $12 \mathrm{~h}$ at $37^{\circ} \mathrm{C}$ in an atmosphere containing $5 \% \mathrm{CO}_{2}$, the supernatant from each well was removed. After washing out non-adherent cells, adherent cells were incubated for $4 \mathrm{~h}$ in medium containing $500 \mu \mathrm{g} / \mathrm{ml}$ 3-(4,5-dimethylthiazol-2-yl)-2,5-diphenyltetrazolium bromide (MTT) solution. The absorbance of the reaction product was measured at $550 \mathrm{~nm}$. Adherent cells were counted in three random area of each well.

Invasion assay. Cell invasion assays were performed using Transwell filter chambers $(8.0-\mu \mathrm{m}$ pores) coated with $1 \%$ gelatin overnight and dried at room temperature. Human CRC cell lines were harvested, washed once in serum-free media, and seeded at $2 \times 10^{5}$ cells in $120 \mu \mathrm{l}$ of medium containing $0.2 \%$ BSA in the upper chamber. Then, $400 \mu \mathrm{l}$ of $0.2 \%$ BSA medium containing $20 \mu \mathrm{g} / \mathrm{ml}$ of human plasma fibronectin (Calbiochem, La Jolla, CA, USA), a chemotactic factor, was loaded into the lower chamber. The Transwell apparatus was incubated for $24 \mathrm{~h}$ at $37^{\circ} \mathrm{C}$. Cells that invaded the bottom surface of the upper chamber were fixed with 70\% ethanol and stained with Diff-Quik solution (Sysmex, Kobe, Japan) following the manufacturer's protocol. The non-invasive cells on the top surface were wiped off with cotton balls, and the stained cells on the bottom surface were counted in five selected fields (each $0.5 \mathrm{~mm}^{2}$ ) of six random squares using a hematocytometer placed on the stage of a light microscope. Results are expressed as the means \pm standard error of the mean (SEM) of the number of cells/field of three individual experiments.

Statistical analysis. The statistical significance of differences between data sets was determined using the paired t-test. The $\lambda^{2}$ and Fisher's exact test, where appropriate, were used to compare expression of leptin with various tumor stages. All reported $p$-values were two-sided and $\mathrm{p} \leq 0.05$ was considered to indicate a statistically significant result. The Statistical Package for the Social Sciences (SPSS)/PC 20.0 (Chicago, IL, USA) was used to perform the calculations. 
A

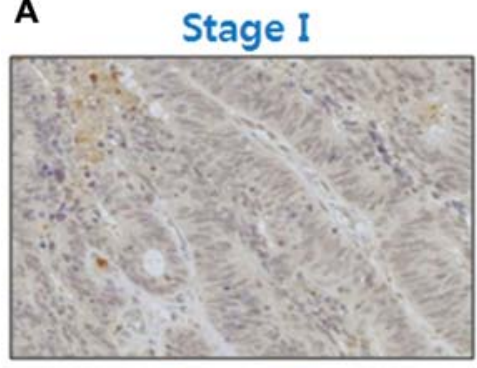

Stage III

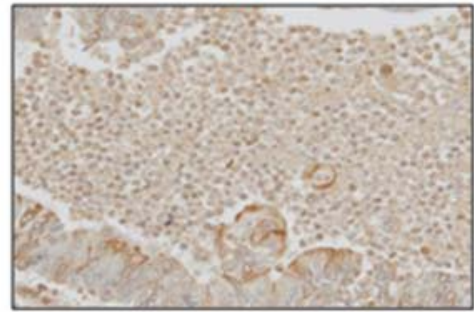

Stage II

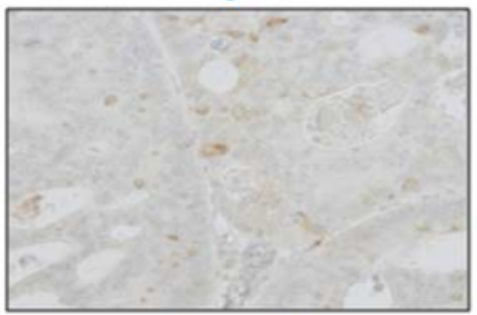

Stage IV

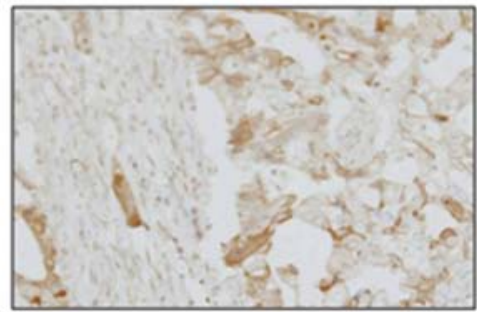

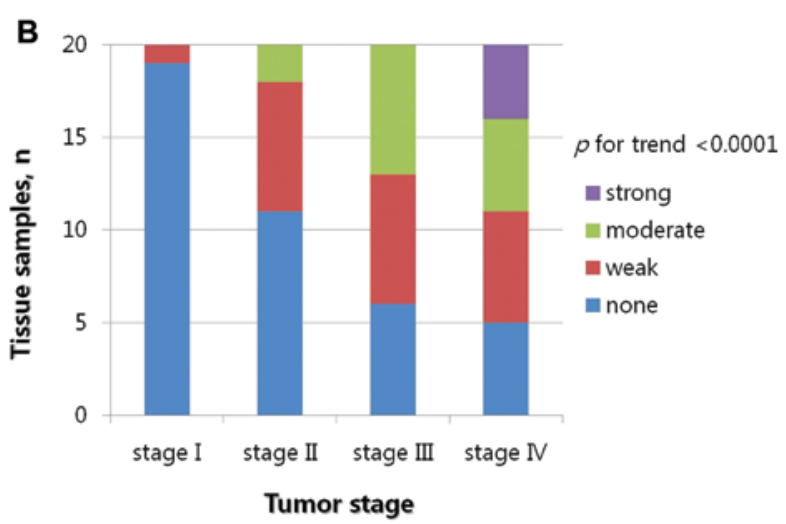

Figure 1. Immunohistochemical detection of leptin expression in human colorectal cancer. (A) In the CRC tissues, leptin was clearly expressed in the cytoplasm of the colorectal cancer gland cells of stage I, II, III and IV, respectively. (B) Leptin expression was undetectable in 19/20 (95\%) patients with stage I CRC and $5 / 20(25 \%)$ patients with stage IV CRC. In contrast, leptin was 'moderately to strongly' expressed in 0/20 tissue samples with stage I CRC and in 10/20 tissue samples with stage IV CRC. Expression of leptin was significantly associated with tumor stage $(\mathrm{p}<0.0001)$.

\section{Results}

Association of leptin expression and tumor stage. We determined the level of expression of leptin in $80 \mathrm{CRCs}$ of different stages. Leptin was clearly expressed in the cytoplasm of the CRC cells. Leptin expression was 'undetectable' in 19/20 (95\%) patients with stage I CRC and 5/20 (25\%) patients with stage IV CRC. In contrast, leptin was 'moderately to strongly' expressed in $0 / 20$ patients with stage I CRC and in 10/20 (50\%) patients with stage IV CRC. Expression of leptin was significantly associated with tumor stage (Fig. 1, p<0.0001).

Spheroid formation induced by leptin. Cancer cells can be cultured in suspension to form spheres in serum-free replacement medium. To test whether human CRC cell lines could form spheres, CaCo-2, LS174T and HCT 116 cells were cultured in a suspension-culture system. Tumorsphere formation by CaCo-2, LS174T and HCT 116 cells was observed on day 5 , accounting for $3.73 \pm 0.25,2.80 \pm 0.26$ and $3.13 \pm 0.32 \%$ of the total cell population by day 11 , respectively. A greater number of large aggregates and colonies formed in the leptintreated cultures relative to the controls $(p<0.05)$. Leptin exposure increased the average colony size formed by each cell line (Fig. 2).

Induction of adhesion and invasion in leptin-treated cells. In the adhesion assays, leptin treatment for $12 \mathrm{~h}$ enhanced cellcell adhesion of HCT 116 cells compared with the untreated HCT 116 cells $(p=0.006)$; however, there was no statistically significant difference between the treated and untreated LS174T ( $p=0.140)$ and CaCo-2 cells ( $p=0.147$, Fig. 3).

We next determined whether leptin treatment influences the invasiveness of the colon cancer cell lines The number of invading HCT 116 cells treated with leptin $(10 \mathrm{ng} / \mathrm{ml})$ was $574.3 \pm 562.5$ when compared with the control value of $502.6 \pm 502.2$ (Fig. $4 \mathrm{~A}, \mathrm{p}=0.178$ ). The number of invading CaCo-2 cells treated with leptin $(10 \mathrm{ng} / \mathrm{ml})$ was $3,395.6 \pm 1571.2$ when compared with the control value of 1,512.6 \pm 850.9 (Fig. 4B, p $<0.001$ ).

Activation of JAK2 and ERK signaling in cells treated with leptin. In the CRC CaCo-2 cells, leptin (10 ng/ml) stimulated the phosphorylation of JAK2 at the different treatment times. Increased phosphorylation of JAK 2 was observed within 
A
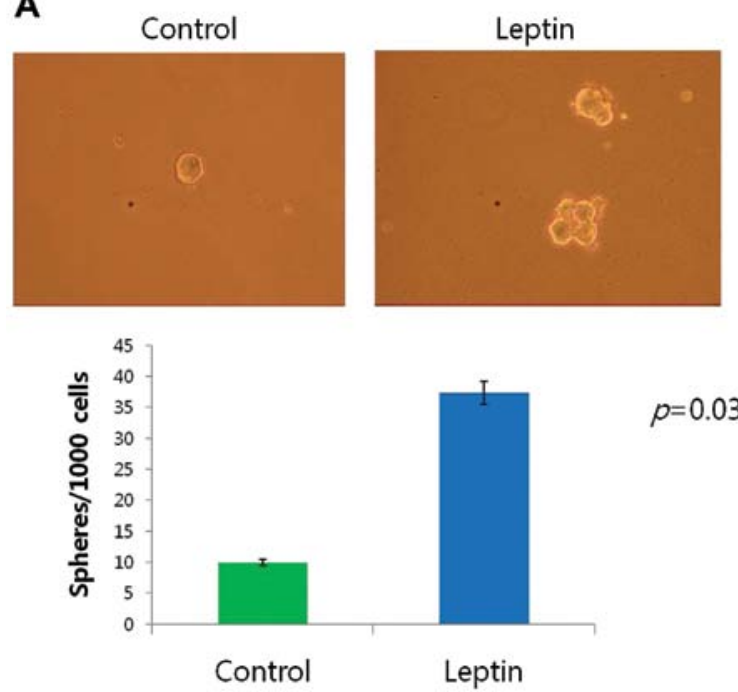

B
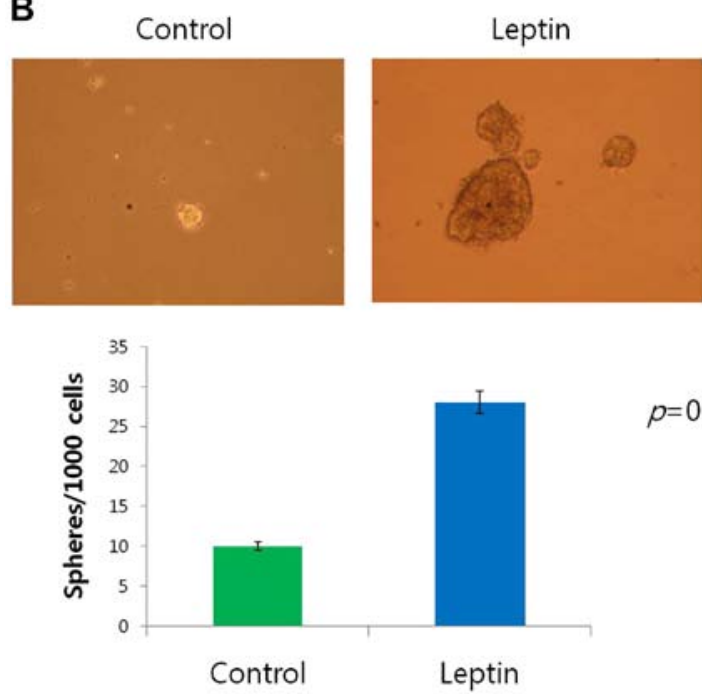

C
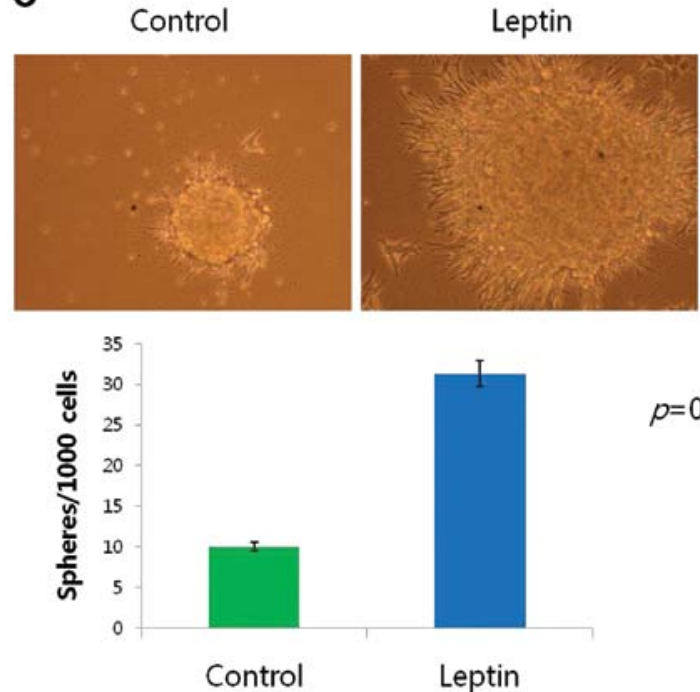

Figure 2. Spheroid formation assays. Leptin increased the number and size of the spheroids in the (A) CaCo-2, (B) LS174T and (C) HCT 116 cell lines.

30 min after leptin treatment followed by a decline. In the LS174T and HCT 116 cells, leptin stimulated the phosphoryla-

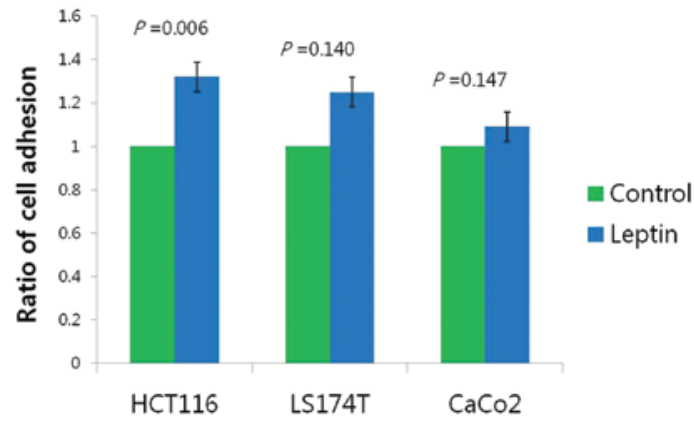

Figure 3. Adhesion assays. Leptin treatment for $12 \mathrm{~h}$ enhanced cell-cell adhesion of HCT 116 cells compared with the untreated HCT 116 cells $(\mathrm{p}=0.006)$, but there were no statistically significant differences between the treated and untreated LS174T $(\mathrm{p}=0.140)$ and $\mathrm{CaCo}-2$ cells $(\mathrm{p}=0.147)$.

tion of ERK. The levels of total (T) JAK2, ERK, MAPK and AKT were not altered in the three CRC cell lines after leptin treatment (Fig. 5).

\section{Discussion}

In the present study, we demonstrated that leptin enhanced the malignant phenotypes of three cell lines derived from human CRCs.

Epidemiologic studies suggest that obesity is a risk factor for colon cancer development $(16,19)$. In contrast, Stattin et al suggested that leptin is simply an innocent bystander, serving merely as a correlate of other obesity-induced adverse alterations in metabolism that may be the true cause of CRC (16). In human CRC tissue, but not in normal mucosa or adenomas, leptin and its receptor are overexpressed, which correlates with the expression of the proneoplastic transcriptional regulator, hypoxia-inducible factor 1 , and a more advanced tumor phenotype $(21,22)$. Moreover, leptin is gradually expressed in the progression of normal cells to adenomas and subsequently to carcinomas, suggesting that leptin may be involved in multistep colorectal carcinogenesis (3).

In the present study, we determined the expression of leptin in tissue samples from 80 Korean patients with CRC and the associated clinicopathologic factors. We showed that patients with more advanced stage tumors expressed higher levels of leptin. Expression levels of leptin and its receptor were previously found to correlate with the grade of tumor differentiation, depth of bowel wall invasion, Dukes' stage and distant metastasis in CRC patients, suggesting that the binding of leptin to its cellular receptor promotes the proliferation of CRC cells (23). However, data for the leptin concentration in the sera of patients with CRC are discrepant. For example, three studies report that decreased serum leptin levels are associated with tumor aggressiveness $(21,24,25)$.

Cancer stem cells are rare, but play an important role in the maintenance of cancer homeostasis (26). Stem cells of the gastrointestinal tract may serve as a principal target of tumorigenic mutations due to their naturally long life-span and capacity for self-renewal. The concept of stem cell-driven tumorigenesis in CRC is supported by the identification and phenotypic characterization of a subpopulation of colon cancer cells capable of initiation and sustained reproduction 

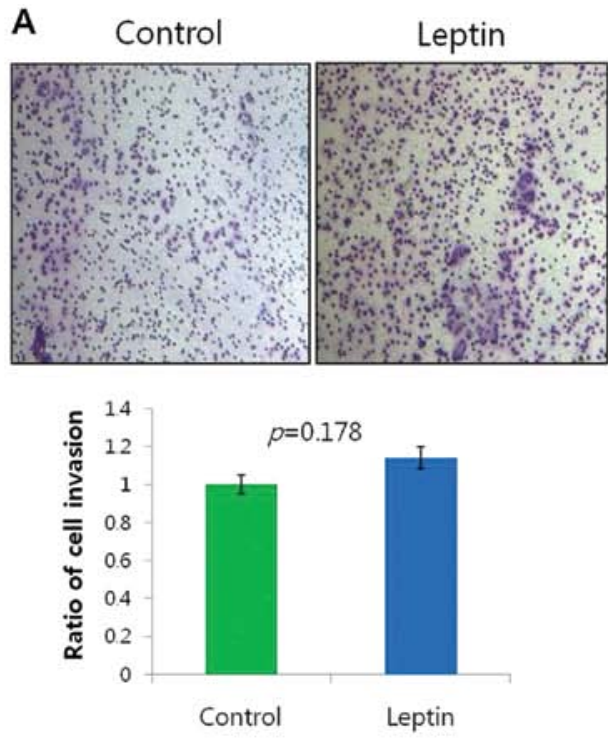

HCT 116
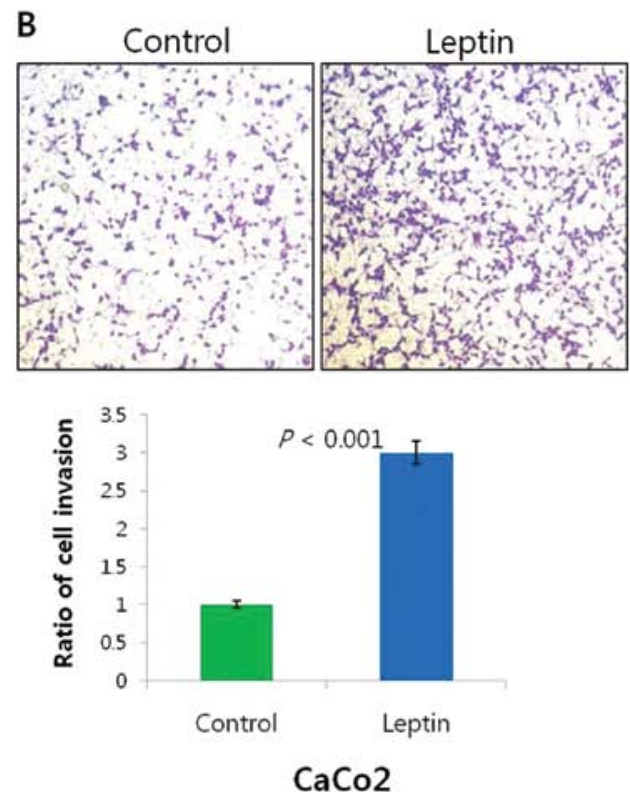

Figure 4. Cell invasion assay. (A) The number of invading leptin-treated $(10 \mathrm{ng} / \mathrm{ml}) \mathrm{HCT} 116$ cells was $574.3 \pm 562.5$, whereas that of the negative control was 502.6 \pm 502.2 ( $\mathrm{p}=0.178$ ). (B) The number of invading leptin-treated $(10 \mathrm{ng} / \mathrm{ml}) \mathrm{CaCo}-2$ cells was $3395.6 \pm 1571.2$, whereas that for the negative control was $1512.6 \pm 850.9(\mathrm{p}<0.001)$.

of human colon carcinomas in immune-compromised mice (tumor-initiating cells or colorectal tumor stem cells) (27). Cancer stem cells (CSCs) form spheres when cultured in vitro in serum-free suspension cultures. This sphere-formation technique was used to isolate putative CSCs from freshly isolated brain (28), breast (29) and colon tumors (30). Furthermore, spheroid culture (or colonospheres) generated from a limited number of human CRC-derived cell lines are enriched for cells that express colonic CSC markers $(31,32)$. Increasing evidence suggests that stem cells play a decisive role in the progression and metastasis of CRC.

CSCs possess the ability to self-renew and differentiate into different cell types. Moreover, CSCs play an important
A Time (min) $\quad 0 \quad 5 \quad 10 \quad 20 \quad 30 \quad 40 \quad 50 \quad 60$

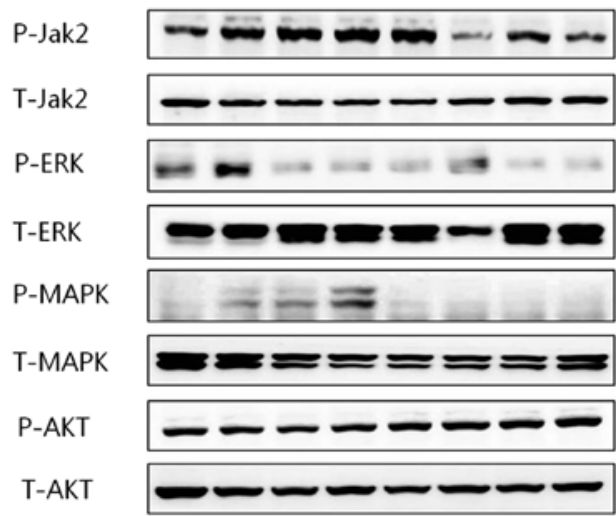

B Time (min) $\quad 0 \quad 5 \quad 10 \quad 20 \quad 30 \quad 40 \quad 50 \quad 60$

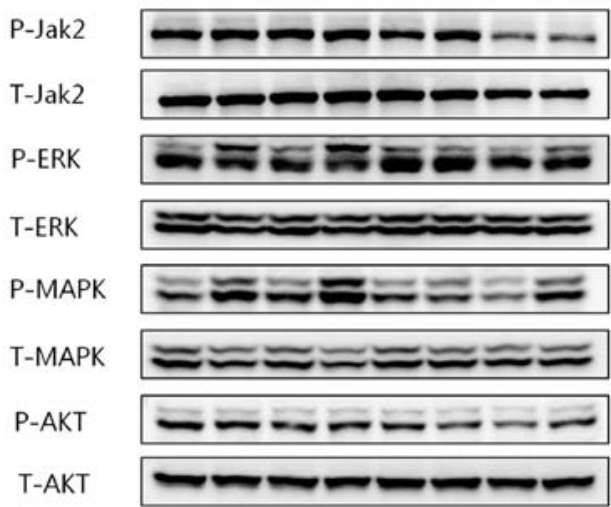

C Time (min) $0 \begin{array}{llllllll} & 5 & 10 & 20 & 30 & 40 & 50 & 60\end{array}$

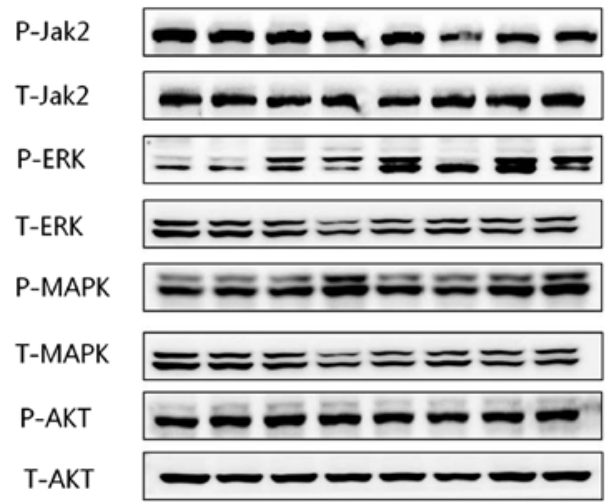

Figure 5. Analysis of JAK and ERK phosphorylation. (A) Leptin stimulated the phosphorylation (P) of JAK2 at different treatment times in CaCo-2 cells. Increased phosphorylation of JAK2 was observed within $30 \mathrm{~min}$ after leptin treatment (10 ng/ml) followed by a decline. (B) In LS174T and (C) HCT 116 cells, leptin stimulated the phosphorylation of ERK. The levels of total (T) JAK2, ERK, MAPK and AKT were not altered in three CRC cell lines following leptin treatment.

role in the maintenance of cancer homeostasis, metastasis, resistance to therapy and subsequent tumor recurrence $(26,33)$. In the present study, leptin increased the number and size of tumorspheres formed by HCT 116, LS174T and CaCo-2 cells. Bartucci et al reported that leptin enhances the formation of tumorsphere by increasing their size and number (27). Therefore, leptin may affect the growth and survival of CRC stem cells that promote colorectal carcinogenesis. 
Cancer progression is a multistep process that enables tumor cells to migrate to points far from a given primary tumor mass (20). Here we showed that leptin enhanced the invasive potential of $\mathrm{CaCo}-2$ cells and the adhesive potential of HCT 116 cells. These effects are consistent with the ability of leptin to enhance the malignant phenotypes of CRC cells, such as local invasiveness and the formation of distant metastasis. Moreover, these results are consistent with our confirmation here of leptin expression in human CRC tissue, which was associated with advanced tumor stage.

To elucidate the signaling pathways involved in leptinmediated induction of malignant properties of CRC cells, we showed that leptin rapidly induced the phosphorylation of JAK2 and ERK, thus activating these key signal transduction pathways associated with cell growth. These results are consistent with those of others that demonstrated the enhanced activation of the JAK/STAT signaling pathway and elevated expression of genes that are targeted by the STAT3 signaling pathway in colorectal adenomas compared with normal colorectal tissues (34). Although we did not study the pharmacologic inhibition of this pathway here, our results suggest that leptin-mediated JAK and ERK signaling may control invasion and migration. Further investigations are required to clarify the role of CSC in the invasion and migration of CRC cells.

Our results were inconsistent regarding adhesion and invasion, signaling pathways and spheroid formation in the three CRC cell lines. These cell lines mirror the features of the original, individual, diverse tumors from which they were derived and reflect different stages of tumors occurring in the same organ as well as their metastatic cells. Therefore, each of these three colon cancer cell lines may possess distinct combinations of unique oncogenes and tumor-suppressor mutations (35).

In conclusion, in the present study, we demonstrated that leptin affected the spheroid formation of colorectal cancer cell lines and regulated adhesion and invasion of colorectal carcinomas through activation of the JAK and ERK signaling pathways.

\section{References}

1. Jemal A, Siegel R, Ward E, et al: Cancer statistics, 2006. CA Cancer J Clin 56: 106-130, 2006.

2. Renehan AG, Tyson M, Egger M, Heller RF and Zwahlen M: Body-mass index and incidence of cancer: a systematic review and meta-analysis of prospective observational studies. Lancet 371: 569-578, 2008.

3. Calle EE and Thun MJ: Obesity and cancer. Oncogene 23: 6365-6378, 2004.

4. Amemori S, Ootani A, Aoki S, et al: Adipocytes and preadipocytes promote the proliferation of colon cancer cells in vitro. Am J Physiol Gastrointest Liver Physiol 292: G923-G929, 2007.

5. Halaas JL, Gajiwala KS, Maffei M, et al: Weight-reducing effects of the plasma protein encoded by the obese gene. Science 269 : 543-546, 1995.

6. Huang L and Li C: Leptin: a multifunctional hormone. Cell Res 10: 81-92, 2000.

7. Somasundar P, McFadden DW, Hileman SM and Vona-Davis L: Leptin is a growth factor in cancer. J Surg Res 116: 337-349, 2004.

8. Zhang F, Chen Y, Heiman M and Dimarchi R: Leptin: structure, function and biology. Vitam Horm 71: 345-372, 2005.

9. Garofalo C and Surmacz E: Leptin and cancer. J Cell Physiol 207: 12-22, 2006.

10. Pai R, Lin C, Tran T and Tarnawski A: Leptin activates STAT and ERK2 pathways and induces gastric cancer cell proliferation. Biochem Biophys Res Commun 331: 984-992, 2005.
11. Rose DP, Komninou D and Stephenson GD: Obesity, adipocytokines, and insulin resistance in breast cancer. Obes Rev 5: 153-165, 2004.

12. Choi JH, Park SH, Leung PC and Choi KC: Expression of leptin receptors and potential effects of leptin on the cell growth and activation of mitogen-activated protein kinases in ovarian cancer cells. J Clin Endocrinol Metab 90: 207-210, 2005.

13. Somasundar P, Frankenberry KA, Skinner H, et al: Prostate cancer cell proliferation is influenced by leptin. J Surg Res 118: 71-82, 2004.

14. Sharma D, Saxena NK, Vertino PM and Anania FA: Leptin promotes the proliferative response and invasiveness in human endometrial cancer cells by activating multiple signal-transduction pathways. Endocr Relat Cancer 13: 629-640, 2006.

15. Stattin P, Palmqvist R, Söderberg S, et al: Plasma leptin and colorectal cancer risk: a prospective study in Northern Sweden. Oncol Rep 10: 2015-2021, 2003.

16. Stattin P, Lukanova A, Biessy C, et al: Obesity and colon cancer: Does leptin provide a link? Int J Cancer 109: 149-152, 2004.

17. Fenton JI, Hursting SD, Perkins SN and Hord NG: Leptin induces an Apc genotype-associated colon epithelial cell chemokine production pattern associated with macrophage chemotaxis and activation. Carcinogenesis 28: 455-464, 2007.

18. Fenton JI, Lavigne JA, Perkins SN, et al: Microarray analysis reveals that leptin induces autocrine/paracrine cascades to promote survival and proliferation of colon epithelial cells in an Apc genotype-dependent fashion. Mol Carcinog 47: 9-21, 2008.

19. Yu F, Yao H, Zhu P, et al: let-7 regulates self renewal and tumorigenicity of breast cancer cells. Cell 131: 1109-1123, 2007.

20. Yamaguchi $\mathbf{H}$, Wyckoff $\mathbf{J}$ and Condeelis $\mathbf{J}$ : Cell migration in tumors. Curr Opin Cell Biol 17: 559-564, 2005.

21. Paik SS, Jang SM, Jang KS, Lee KH, Choi D and Jang SJ: Leptin expression correlates with favorable clinicopathologic phenotype and better prognosis in colorectal adenocarcinoma. Ann Surg Oncol 16: 297-303, 2009.

22. Koda M, Sulkowska M, Kanczuga-Koda L, Surmacz E and Sulkowski S: Overexpression of the obesity hormone leptin in human colorectal cancer. J Clin Pathol 60: 902-906, 2007.

23. Liu H, Wan D, Pan Z, et al: Expression and biological significance of leptin, leptin receptor, VEGF, and CD34 in colorectal carcinoma. Cell Biochem Biophys 60: 241-244, 2011.

24. Bolukbas FF, Kilic H, Bolukbas C, et al: Serum leptin concentration and advanced gastrointestinal cancers: a case controlled study. BMC Cancer 4: 29, 2004.

25. Sălăgeanu A, Tucureanu C, Lerescu L, et al: Serum levels of adipokines resistin and leptin in patients with colon cancer. J Med Life 3: 416-420, 2010.

26. Scopelliti A, Cammareri P, Catalano V, Saladino V, Todaro M and Stassi G: Therapeutic implications of cancer initiating cells. Expert Opin Biol Ther 9: 1005-1016, 2009.

27. Bartucci M, Svensson S, Ricci-Vitiani L, et al: Obesity hormone leptin induces growth and interferes with the cytotoxic effects of 5-fluorouracil in colorectal tumor stem cells. Endocr Relat Cancer 17: 823-833, 2010.

28. Singh SK, Hawkins C, Clarke ID, et al: Identification of human brain tumour initiating cells. Nature 432: 396-401, 2004.

29. Dey D, Saxena M, Paranjape AN, et al: Phenotypic and functional characterization of human mammary stem/progenitor cells in long term culture. PLoS One 4: e5329, 2009.

30. Todaro M, Alea MP, Di Stefano AB, et al: Colon cancer stem cells dictate tumor growth and resist cell death by production of interleukin-4. Cell Stem Cell 1: 389-402, 2007.

31. Fan X, Ouyang N, Teng H and Yao H: Isolation and characterization of spheroid cells from the HT29 colon cancer cell line. Int J Colorectal Dis 26: 1279-1285, 2011.

32. Kanwar SS, Yu Y, Nautiyal J, Patel BB and Majumdar AP: The Wnt/ $\beta$-catenin pathway regulates growth and maintenance of colonospheres. Mol Cancer 9: 212, 2010.

33. O'Brien CA, Pollett A, Gallinger S and Dick JE: A human colon cancer cell capable of initiating tumour growth in immunodeficient mice. Nature 445: 106-110, 2007.

34. Uchiyama T, Takahashi H, Sugiyama M, et al: Leptin receptor is involved in STAT3 activation in human colorectal adenoma. Cancer Sci 102: 367-372, 2011.

35. Vécsey-Semjén B, Becker KF, Sinski A, et al: Novel colon cancer cell lines leading to better understanding of the diversity of respective primary cancers. Oncogene 21: 4646-4662, 2002. 